\title{
Digestion of Human Milk Lipids: Physiologic Significance of sn-2 Monoacylglycerol Hydrolysis by Bile Salt-Stimulated Lipase
}

\author{
OLLE HERNELL ${ }^{(40)}$ AND LARS BLÄCKBERG
}

Department of Pediatrics and Department of Physiological Chemistry, University of Umea, S-901 85 Umea, Sweden

\begin{abstract}
Summary
The bile salt-stimulated lipase secreted with human milk was found to be devoid of positional specificity, i.e., it hydrolyzed emulsified triacylglycerols to glycerol and fatty acids. It also hydrolyzed micellar sn-2 monoacylglycerols. This is in contrast to pancreatic lipase which has a pronounced preferrance for hydrolysis of sn- 1 and sn-3 ester bonds. When the two enzymes were operating together, as in the intestine of the infant fed raw human milk, the sn-2 monoacylglycerols formed by pancreatic lipase served as an excellent substrate for bile salt-stimulated lipase. Thus, the end products of triacylglycerol hydrolysis became glycerol and fatty acids and not sn-2 monoacylglycerol and fatty acids. The bile salt-stimulated lipase also catalyzed incorporation of fatty acids into acylglycerols to a much lesser extent than did pancreatic lipase. Together these two effects of bile salt-stimulated lipase have a promoting effect on the overall process of intraluminal lipolysis.

In newborn infants, with low intraduodenal bile salt concentrations, glycerol and fatty acids also should be more readily absorbed than monoacylglycerol and fatty acids. Thus, by serving as a complement to pancreatic lipase, bile salt-stimulated lipase can ensure efficient utilization of milk lipids also in infants with immature endogenous mechanisms for fat digestion and absorption.
\end{abstract}

In the healthy human adult, digestion and absorption of dietary fat is almost complete, i.e., at least $95 \%$ of consumed fat is absorbed. The corresponding figures reported for newborn infants vary widely but, are especially for preterm infants often considerably lower $(9,11,12,30,34,38)$. In these infants an impaired overall process of fat digestion and absorption has been attributed mainly to low intraduodenal concentrations of pancreatic lipase $(15,27,39)$ and bile salts $(8,26,35)$.

Human milk contains a potent lipase, the bile salt-stimulated lipase, which supplement the low pancreatic lipase concentrations (16, for review see 18,19$)$. This can explain why human milk fat is more efficiently utilized than fat from formulas based on cow's milk $(12,23,37)$. Strong evidence that the bile salt-stimulated lipase has an important role in the digestion of milk lipids in the newborn comes from the recent observation that heat-treatment of human milk reduces fat absorption by approximately one third in preterm infants $(1,38)$. Previous studies have established that this lipase contributes to hydrolysis of milk triacylglycerols and vitamin A esters $(14,17)$. An additional, perhaps more important role of this lipase, might be to hydrolyze the monoacylglycerols generated by pancreatic lipase. Due to its positional specificity, pancreatic lipase hydrolyzes only two of the three ester bonds in a triacylglycerol molecule $(7,24)$. Furthermore, this enzyme catalyzes not only hydrolysis but also esterification (4). Therefore, it soon reaches an equilibrium state where the rate of formation of di- and triacylglycerols by acylation of monoacylglycerols equals the rate of hydrolysis. Further progress of the reaction depends on the solubilization of the monoacylglycerols by bile salts and subsequent absorption. The low intraduodenal bile salt concentration in newborns may make this a slow process which thus limits overall fat absorption. In a previous study, with a crude preparation of bile salt-stimulated lipase from human milk, we found that this lipase hydrolyzed all three ester bonds in a triacylglycerol molecule $(20)$. In the present study we confirm this with a pure enzyme and demonstrate that this lipase can efficiently hydrolyze the monoacylglycerols generated by pancreatic lipase thus driving hydrolysis towards completion.

\section{MATERIALS AND METHODS}

Sodium taurocholate, tri[9,10(n)- $\left.{ }^{3} \mathrm{H}\right]$ oleylglycerol, trioleyl[2(n)$\left.{ }^{3} \mathrm{H}\right]$-glycerol, $\left[9,10(\mathrm{n})-{ }^{3} \mathrm{H}\right]$ oleic acid, monooleyl [2(n)- $\left.{ }^{3} \mathrm{H}\right]$ glycerol, unlabeled oleic acid and monooleylglycerol were prepared by $\mathrm{Dr}$. L. Krabisch, Lund, Sweden. The labeled and unlabeled lipids were purified by thin layer chromatography before use. Sodium deoxycholate was obtained from Merck, Darmstadt, Germany and gum arabic was from Sigma Chemical Co., St. Louis, Mo., USA. Bile salt-stimulated lipase was purified from human milk as previously described (3) and porcine pancreatic lipase, purified as described (36), was a generous gift from Dr. R. Verger, Marseille, France. The specific activities were 50 and $300 \mu$ mole fatty acid released per min and $\mathrm{mg}$ protein (trioleylglycerol/gum arabic emulsion, pH 6.5) for the respective lipase. Duodenal contents was obtained from one fasting healthy adult as previously described (13).

Determination of triacylglycerol hydrolyzing activity. The triacylglycerol emulsion was prepared with trioleylglycerol in gum arabic as described (3). The standard incubation mixture contained 1.6 $\times 10^{6} \mathrm{cpm}$ of tri $\left[9,10(\mathrm{n}){ }^{3} \mathrm{H}\right]$ oleylglycerol and $4.0 \mathrm{mg}$ unlabeled triacylglycerol per $\mathrm{ml}$, and was $0.15 \mathrm{M}$ in $\mathrm{NaCl}, 5 \mathrm{mM}$ in $\mathrm{CaCl}_{2}$ and $0.1 \mathrm{M}$ in Tris-Maleate, $\mathrm{pH}$ 6.5. Further additions were as indicated in legends to tables and figures. The incubations were carried out in a water bath shaking at 50 strokes $/$ min at $37^{\circ} \mathrm{C}$. The fatty acids released were extracted (2) and their radioactivity determined.

To determine the composition of the reaction products $\left[{ }^{3} \mathrm{H}\right]-$ glycerol labeled trioleylglycerol was used instead of $\left[{ }^{3} \mathrm{H}\right]$-oleic acid labeled trioleylglycerol. Extraction of lipids and separation of glycerol and acylglycerols were as previously described (20). Because the trioleylglycerol was labeled in the glycerol moiety no values of free fatty acids were recorded in these experiments. To estimate the amount of free fatty acid incorporated into acylglycerols, the emulsion was prepared with unlabeled trioleylglycerol and a trace amount of tritiated oleic acid.

Determination of monoacylglycerol hydrolyzing activity. Monoacylglycerol micelles were prepared essentially as described by Thornqvist et al. (32) using either randomized monooleyl-glycerol [ $92 \%$ sn-1(3) and $8 \%$ sn-2] or purified sn-2 monooleyl-glycerol. The detergents used were deoxycholate (final concentration 3 
$\mathrm{mM}$ ), or oleic acid $0.9 \mathrm{mg} / \mathrm{ml}$. sn-2 Monooleylglycerol was prepared by thin layer chromatography (31) immediately before use. The final incubation mixtures contained $1.75 \mathrm{mg}$ monooleylglycerol per $\mathrm{ml}$ and was $0.15 \mathrm{M}$ in $\mathrm{NaCl}, 5 \mathrm{mM}$ in $\mathrm{CaCl}_{2}$ and $0.1 \mathrm{M}$ in Tris-Maleate, $\mathrm{pH}$ 6.5. Further additions were as indicated in legends to tables and figures. Incubations were at $37^{\circ} \mathrm{C}$ and the glycerol formed was extracted and the radioactivity determined (31).

\section{RESULTS}

Differencies in composition of reaction products formed during triacylglycerol hydrolysis by pancreatic lipase and by bile salt-stimulated lipase. To exclude that the difference in positional specificity between pancreatic lipase and bile salt-stimulated lipase observed in a previous study (20) was due to impurities in the enzyme preparation and/or differencies in assay conditions we incubated an emulsion of trioleylglycerol with purified pancreatic lipase or bile salt-stimulated lipase under identical conditions. During hydrolysis by pancreatic lipase monoacylglycerol became the major partial glyceride formed whereas there was only a slow release of glycerol. In contrast, during hydrolysis by bile salt-stimulated lipase, there was a rapid release of free glycerol which, became the major labeled product formed. After $2 \mathrm{~h}$ of incubation, when more than $80 \%$ of the triacylglycerols had been hydrolyzed, glycerol accounted for 40 mole\% of labeled products to compare with $6 \mathrm{~mole} \%$ in the experiment with pancreatic lipase. The corresponding figures for monoacylglycerols were 28 and 54 mole $\%$ respectively (Table 1).

Hydrolysis of monoacylglycerols by bile salt-stimulated lipase. The bile salt-stimulated lipase readily hydrolyzed both randomized and sn-2 monooleylglycerol. The specific activities were similar (Table 2) further demonstrating the lack of positional specificity. The rates were about one third of that recorded with a trioleylglycerol/gum arabic emulsion. No marked difference was seen if deoxycholate was exchanged for oleic acid as stabilizing agent.

The bile salt dependency of the lipase was tested using random-

Table 1. Composition of reaction products formed during triacylglycerol hydrolysis by pancreatic lipase or bile saltstimulated lipase

\begin{tabular}{lcc}
\hline Labeled compound & Pancreatic lipase & $\begin{array}{c}\text { Bile salt-stimulated li- } \\
\text { pase }\end{array}$ \\
\hline Triacylglycerol & $10.4^{1}$ & 14.1 \\
Diacylglycerol & 30.4 & 17.1 \\
Monoacylglycerol & 53.5 & 28.2 \\
Glycerol & 5.7 & 40.6 \\
\hline
\end{tabular}

${ }^{1}$ Values are given in mole $\%$ and refer to relative concentration after incubation with either pancratic lipase $(1 \mu \mathrm{g} / \mathrm{ml})$ or bile salt-stimulated lipase $(6 \mu \mathrm{g} / \mathrm{ml})$. Enzyme concentrations were chosen to give the same degree of hydrolysis. The composition of reaction products was determined at various times during the incubations. The data presented refer to values obtained after $2 \mathrm{~h}$. Incubations were $5 \mathrm{mM}$ in sodium taurocholate.

Table 2. Hydrolysis of emulsified trioleylglycerol and micellar monooleylglycerol by bile salt-stimulated lipase

\begin{tabular}{lc}
\hline \multicolumn{1}{c}{ Substrate $^{\prime}$} & Specific activity $^{2}$ \\
\hline Trioleylglycerol/gum arabic & $50(48-53)$ \\
sn-1(3)-monooleylglycerol/deoxycholate & $21(18-22)$ \\
sn-1(3)-monooleylglycerol/oleic acid & $14(13-17)$ \\
sn-2-monooleyglycerol/deoxycholate & $16(14-18)$ \\
\hline
\end{tabular}

${ }^{1}$ Preparation of substrates and other conditions were as described under "Materials and Methods." The sodium taurocholate concentration was 2 $\mathrm{mM}$ except with trioleylglycerol/gum arabic where it was $5 \mathrm{mM}$.

${ }^{2}$ Values are expressed as $\mu$ mole fatty acid released per min and $\mathrm{mg}$ protein and represent the mean of four determinations with the range given within parentheses.

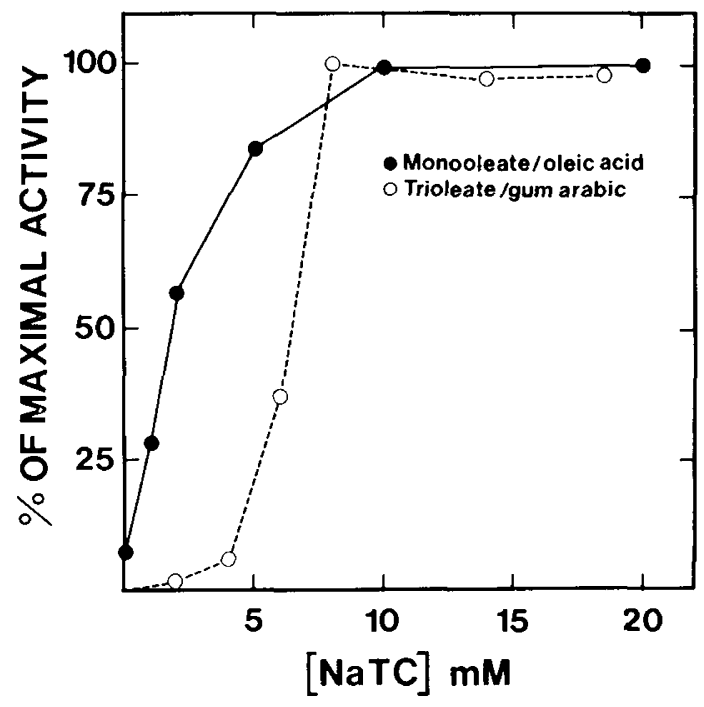

Fig. 1. Effect of bile salt on the activity of bile salt-stimulated lipase against emulsified triacylglycerol and micellar monoacylglycerol. Trioleylglycerol/gum arabic emulsion and monooleylglycerol micelles stabilized with oleic acid were prepared as described under "Materials and Methods." Conditions were: $\mathrm{pH} 6.5,5 \mathrm{mM} \mathrm{CaCl}_{2}$, and $0.15 \mathrm{M} \mathrm{NaCl}$. The concentration of sodium taurocholate (NaTC) was varied. Values are expressed as $\%$ of the maximum.

ized monooleylglycerol stabilized with oleic acid. A low but significant activity was recorded in the absence of bile salt (Fig. 1). This is in contrast to hydrolysis of the trioleylglycerol/gum arabic emulsion where bile salts are a prerequisite. A high rate of hydrolysis was obtained with a lower bile salt concentration when monooleylglycerol was the substrate (Fig. 1). The same principal results were found using other types of monoacylglycerol micelles, e.g., stabilized with Triton X-100 (data not shown).

The promoting effect of bile salt-stimulated lipase on intraluminal lipolysis. The combined effect of the two lipases was studied with an emulsion of trioleylglycerol in gum arabic. During incubation with pancreatic lipase there was only a slow release of free glycerol and, monoacylglycerol was the major labeled product formed. A second addition of pancreatic lipase caused no evident change in composition of products formed (Fig. 2 a). In contrast, if bile saltstimulated lipase was added after $60 \mathrm{~min}$ of incubation with pancreatic lipase, this initiated a rapid release of glycerol which, in fact became the major labeled product formed (Fig. $2 \mathrm{~b}$ ).

To further mimic the situation in vivo an experiment was carried out with duodenal juice rather than purified enzyme as source of pancreatic lipase and with a final bile salt concentration of $2 \mathrm{mM}$ taurocholate. After $60 \mathrm{~min}$ of incubation with duodenal juice purified bile salt-stimulated lipase was added to one of the two sets of incubation mixtures. The same principal observation was made; a rapid and continuous release of glycerol with a concomitant decrease in relative concentrations of di- and monoacylglycerols as compared with control incubations with only duodenal juice as enzyme source (Fig. 3). Before addition of bile saltstimulated lipase (i.e., at $60 \mathrm{~min}$ of incubation) 2-monoacylglycerol constituted more than $80 \%$ of the total monoacylglycerol released. After the addition the relative concentration of monoacylglycerols decreased to less than 20 mole\% demonstrating the ability of bile salt-stimulated lipase to hydrolyze sn-2 monoacylglycerols also under these more physiologic conditions.

Table 3 examplifies the ability of pancreatic lipase to catalyze the incorporation of fatty acids into acylglycerols, i.e., the reverse reaction to hydrolysis. When about one-fourth of total ester bonds had been hydrolyzed (estimated from parallel incubations with labeled trioleylglycerol) about $25 \%$ of labeled oleic acid had been incorporated into di- and triacylglycerols. Under identical conditions with bile salt-stimulated lipase, only $7 \%$ of labeled oleic acid was found in acylglycerols (Table 3). 


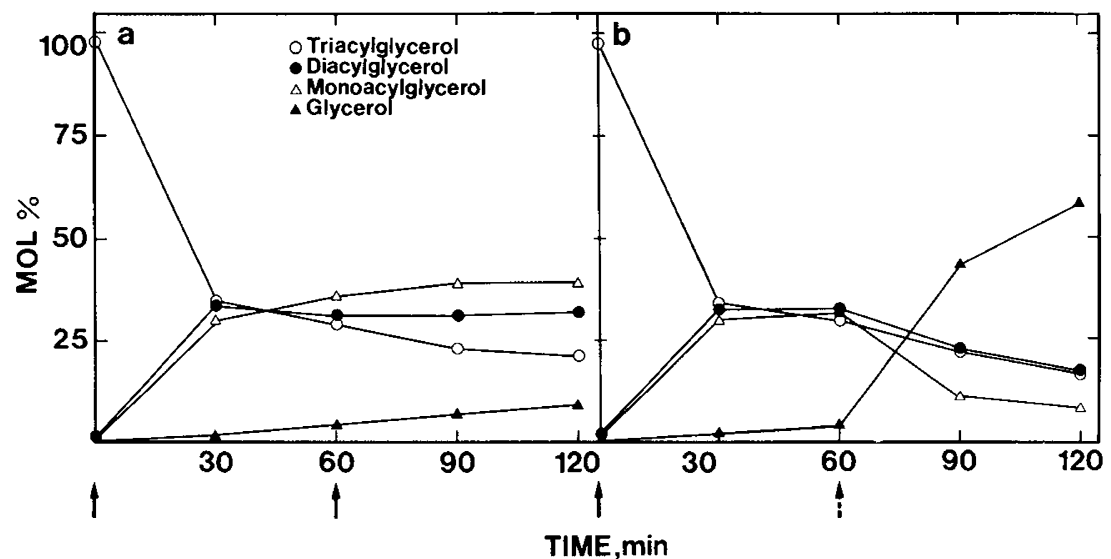

Fig. 2. The combined effect of pancreatic lipase and bile salt-stimulated lipase on triacylglycerol hydrolysis. Conditions were as described under "Materials and Methods." Sodium taurocholate was added to $5 \mathrm{mM}$. Pancreatic lipase $(1 \mu \mathrm{g} / \mathrm{ml})$ was added at 0 min $(a$ and $b)$ and at 60 min $(a)$ as indicated by the solid arrows. Bile salt-stimulated lipase $(6 \mu \mathrm{g} / \mathrm{ml})$ was added at $60 \mathrm{~min}(b)$ as indicated by the broken arrow. At different times samples were collected and the composition of reaction products determined. Enzyme concentrations were chosen to give the same degree of hydrolysis in comparable individual incubations.

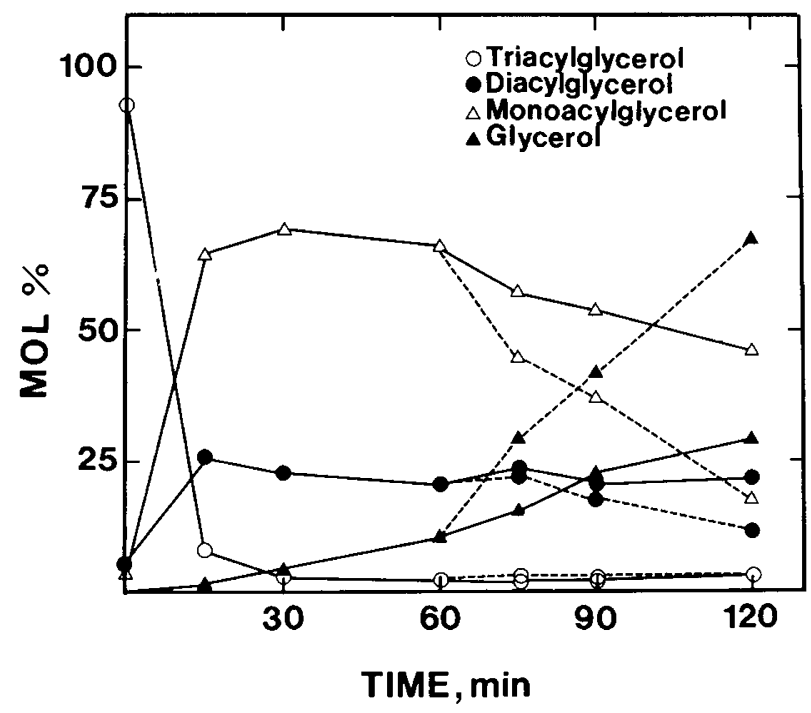

Fig. 3. Effect on the progress of triacylglycerol hydrolysis by combining duodenal juice and bile salt-stimulated lipase. Conditions were as described under "Materials and Methods" but the incubations were $2 \mathrm{mM}$ in sodium taurocholate. Duodenal juice $(25 \mu \mathrm{l} / \mathrm{ml})$ was added to two sets of tubes at 0 min (solid line). Bile salt-stimulated lipase $(4 \mu \mathrm{g} / \mathrm{ml}$ ) was added at $60 \mathrm{~min}$ to one set (broken line). At different times samples were withdrawn and the composition of labeled products determined.

Table 3. Incorporation of $\left.{ }^{3} \mathrm{H}\right]$-oleic acid into acylglycerols by bile salt-stimulated lipase or pancreatic lipase

\begin{tabular}{lcc}
\hline Labeled compound & Pancreatic lipase & $\begin{array}{c}\text { Bile salt-stimulated li- } \\
\text { pase }\end{array}$ \\
\hline Fatty acid & $73.5^{1}$ & 93.0 \\
Monoacylglycerol & 0.5 & 3.5 \\
Diacylglycerol & 14.5 & 2.5 \\
Triacylglycerol & 11.5 & 1.0 \\
\hline
\end{tabular}

${ }^{1}$ The values are expressed in $\%$ of total fatty acid radioactivity. The distribution of radioactivity was determined at various times during the incubations. The data presented refer to values obtained when, in parallel incubations, $25 \%$ of the ester bonds had been hydrolyzed.

\section{DISCUSSION}

The bile salt-stimulated lipase has properties that makes it well suited for a function in the small intestine $(17,18)$. It hydrolyzes human milk triacylglycerols under the conditions prevailing in the small intestine of the human neonate and, in infants fed raw milk, it can give a substantial contribution to the triacylglycerol and retinol ester hydrolyzing activities in duodenal contents (14). Although not unambiguous (30) there is evidence from studies in vivo of its beneficial effect on utilization of milk fat $(1,37,38)$. In the present study we explored the possibility that bile salt-stimulated lipase not only augments the endogenous lipid digestion but also serves as its complement.

In contrast to pancreatic lipase bile salt-stimulated lipase was found to be devoid of positional specificity, i.e., it hydrolyzed sn2 monoacylglycerols. This difference between the two lipases became evident when they were operating together as in the breast-fed infant. Pancreatic lipase alone or duodenal juice hydrolyzed an emulsion of triacylglycerol to mainly 2-monoacylglycerol and fatty acid. When bile salt-stimulated lipase was added to such mixtures it hydrolyzed the 2-monoacylglycerols so that the final products of lipolysis became glycerol and fatty acids, i.e., 2-monoacylglycerols served as an excellent substrate for bile salt-stimulated lipase. It seems therefore as if the principal effect of bile salt-stimulted lipase is to complete acylglycerol hydrolysis. This is independent of whether the 2-monoacylglycerols are present in the oil phase or in micellar solution. In that respect it is an interesting observation that lower bile salt concentrations were required for rapid hydrolysis rate of micellar solution than of emulsions.

Pancreatic lipase not only catalyzes triacylglycerol hydrolysis but also the reverse reaction, i.e., incorporation of fatty acids into acylglycerols (4). Therefore, lipolysis proceeds until the two reactions are operating at the same rate. This is illustrated in Fig. 2a where further addition of pancreatic lipase had no effect on net lipolysis. Bile salt-stimulated lipase catalyzed the incorporation of fatty acids into acylglycerols to a much lesser extent. During lipolysis this enzyme will also progressively hydrolyze monoacylglycerols to glycerol. Because glycerol is water soluble it is released from the oil into the water, and will no longer be available for esterification. Thus, when the two enzymes are combined an important effect of bile salt-stimulated lipase would be to improve lipolysis by driving it towards hydrolysis.

A more efficient utilization of triacylglycerols from human milk than from formulas based on cow's milk $(12,23,37)$ has previously been attributed mainly to the particular fatty acid pattern of human milk triacylglycerols with palmitic acid esterified preferentially in the sn-2 position (6). Thus, due to the positional specificity of pancreatic lipase a high proportion of palmitic acid would be absorbed as monopalmitoylglycerol rather than as palmitic acid. This was found to $\mathrm{z}$ favour absorption of palmitic acid 
both in rats (33) and in newborn infants (10); however, because solubility of monoacylglycerol in an aqueous phase is sharply increased with increased bile salt concentration (21) a more efficient absorption of 2-monoacylglycerol than of free fatty acid can probably only be expected in a situation when efficient micellar solubilization is possible, i.e., when the intraduodenal bile salt concentration is relatively high. This should be especially relevant for a long-chain saturated fatty acid, e.g., palmitic acid. Mixed micelles transport the products of lipolysis to the intestinal mucosa for absorption (5). Newborn infants, especially preterm infants, have low intraduodenal bile salt concentrations, close to or even below that required for micelle formation $(8,26,35)$. Thus, in these infants the capacity to solubilize monoacylglycerols and fatty acids in micellar form is considerably reduced compared to adults. Interestingly, when intraduodenal bile salt concentrations are low fatty acids are more readily absorbed than are monoacylglycerols $(22,25)$. This probably reflects a change in distribution between the oil and aqueous phases of fatty acids and monoacylglycerols when intraluminal bile salt concentrations decrease. Scow et al. (28) found that more oleic acid than monooleylglycerol was released into the aqueous phase, when a monolayer of trioleylglycerol was hydrolyzed in the absence of bile salts. The ratio of oleic acid to monooleylglycerol was 33 in the aqueous phase while it was 1.5 in the lipid phase. Complete hydrolysis of triacylglycerols to glycerol and fatty acids will thus favour lipid absorption when intraduodenal bile salt concentrations are low, e.g., in the human neonate. The combined action of pancreatic lipase and bile salt-stimulated lipase gives such complete hydrolysis. The physiologic relevance of this is supported by the observation of Signer et al. (29) who found no correlation between fat absorption and intraduodenal bile salt levels in premature infants fed human milk whereas there was a strong such correlation when the infants were fed cow's milk based formula.

The secretion of bile salt-stimulated lipase with the milk of the highest primates seems to be an adaptation to the specific situation in the gastrointestinal tract of their newborn offsprings. This lipase supplements the low pancreatic lipase activities. It also hydrolyzes the monoacylglycerols produced through the action of pancreatic lipase. This drives hydrolysis to completion, and ensures efficient absorption of milk lipids also in infants with low intraduodenal bile salt concentrations.

\section{REFERENCES AND NOTES}

1. Atkinson, S. A., Bryan, M. H., and Anderson, G. H.: Human milk feeding in premature infants: protein, fat and carbohydrate balances in the first two weeks of life. J. Pediatr., 99: 617 (1981).

2. Belfrage, $\mathbf{P}$. and Vaughan, $\mathbf{M}$.: Simple liquid-liquid partition system for isolation of labeled oleic acid from mixtures with glycerides. J. Lipid Res., 10: 341 (1969).

3. Bläckberg, L. and Hernell, O.: The bile salt-stimulated lipase in human milk: purification and characterization. Eur. J. Biochem., 116: 221 (1981)

4. Borgström, B.: On the mechanism of pancreatic lipolysis of glycerides. Biochim. Biophys. Acta, 13: 491 (1954).

5. Borgström, B.: Digestion and absorption of lipids. In: R. K. Crane: International Review of Physiology, Gatrointestinal Physiology II: Vol. 12, p. 305 (University Park Press, Baltimore, 1977)

6. Breckenridge, W. C., Marai, L., and Kuksis, A.: Triglyceride structure of human milk fat. Can. J. Biochem., 47: 761 (1969).

7. Brockerhoff, H.: Substrate specificity of pancreatic lipase. Biochim. Biophys. Acta, 159: 296 (1968).

8. Brueton, M. J., Berger, H. M., Brown, G. A., Ablitt, L., Iyngkaran, N., and Wharton, B. A.: Duodenal bile acid conjugation patterns and dietary sulphur amino acids in the newborn. Gut, 19: 95 (1978).

9. Davidsson, M. and Bauer, C. H.: Patterns of fat excretion in feces of premature infants fed various preparations of milk. Pediatrics, 25: 375 (1960).

10. Filer, L. J. Jr., Mattson, F. H., and Fomon, S. J.: Triglyceride configuration and fat absorption by the human infant. J. Nutr., 99: 293 (1969).
11. Fomon, S. J.: Infant Nutrition (Saunders, Philadelphia, 1967).

12. Fomon, S. J., Ziegler, E. E., Thomas, L. M., Jensen, R. L., and Filer, L. J.: Excretion of fat by normal full-term infants fed various milk and formulas. Amer. J. Clin. Nutr., 28: 1299 (1970).

13. Fredrikzon, B. and Hernell, O.: Role of feeding on lipase activity in gastric contents. Acta Paediatr. Scand., 66: 479 (1977).

14. Fredrikzon, B., Hernell, O., Bläckberg, L., and Olivercrona, T.: The bile saltstimulated lipase in human milk: Evidence of activity in vivo and of a role in the digestion of milk retinol esters. Pediatr. Res., 12: 1048 (1978).

15. Fredrikzon, B. and Olivecrona, T.: Decrease of lipase and esterase activities in intestinal contents of newborn infants during test meals. Pediatr. Res., 12: 631 (1978).

16. Freudenberg, E.: Die Frauenmilch-Lipase (S. Karger, Basel, 1953).

17. Hernell, O.: Human milk lipases. Ill. Physiological implications of the bile saltstimulated lipase. Eur. J. Clin. Invest., 5: 267 (1975).

18. Hernell, O., Bläckberg, L., Fredrikzon, B., and Olivecrona, T.: The bile saltstimulated lipase in human milk and lipid digestion in the neonatal period. In: E. Lebenthal: Textbook of Gastroenterology and Nutrition in Infancy. Vol. 1, p. 465, (Raven Press, New York, 1981).

19. Hernell, O., Bläckberg, L., and Olivecrona, T.: Human milk lipases. In: E. Lebenthal: Textbook of Gastroenterology and Nutrition in Infancy. Vol. 1, p 347, (Raven Press, New York, 1981).

20. Hernell, O. and Olivecrona, T.: Human milk lipases. II. Bile salt-stimulated lipase. Biochim. Biophys. Acta, 369: 234 (1974).

21. Hofmann, A. F.: The behaviour and solubility of monoglycerides in dilute, micellar bile-salt solution. Biochim. Biophys. Acta, 70: 306 (1963)

22. Hofmann, A. F. and Mekhjian, H. S.: Bile acids and the intestinal absorption of fat and electrolytes in health and disease. In: P. P. Nair and D. Kritchevsky: The Bile Acids, p. 103 (Plenum Press, New York, 1971).

23. Holt, L. E. Jr., Tidwell, H. C., Kirk, C. M., Cross, D. M., and Neale, S.: Studies in fat metabolism. I. Fat absorption in normal infants. J. Pediat., 6: 427 (1935).

24. Mattson, F. H. and Volpenhein, R. A.: Hydrolysis of primary and secondary esters of glycerol by pancreatic juice. J. Lipid Res., 9: 79 (1968).

25. Morgan, R. G. H. and Borgström, B.: The mechanism of fat absorption in the bile fistula rat. Q. J. Exp. Physiol., 54: 228 (1969).

26. Murphy, G. M. and Signer, E.: Bile acid metabolism in infants and children. Gut, 15: 151 (1974).

27. Norman, A., Strandvik, B., and Ojamäe, Ö.: Bile acids and pancreatic enzymes during absorption in the newborn. Acta Paediatr. Scand., 61: 571 (1972).

28. Scow, R. O., Desnuelle, P., and Verger, R.: Lipolysis and lipid movement in a membrane model. J. Biol. Chem., 254: 6456 (1979).

29. Signer, E., Murphy, G. M., Edkins, S., and Andersson, C. M.: Role of bile salts in fat malabsorption of premature infants. Arch. Dis. Child., 49: 174 (1974).

30. Söderhjelm, L.: Fat absorption studies in children. 1. Influence of heat treatment of milk on fat retention by premature infants. Acta Paediatr. Scand., 41: 207 (1952).

31. Thomas, A. E. III., Scharoun, J. E., and Ralston, H.: Quantitative estimation of isomeric monoglycerides by thin layer chromatography. J. Amer. Oil Chem. Soc., 42 : 789 (1965).

32. Thornqvist, H., Krabisch, L., and Belfrage, P.: Simple assay for monoacylglycerol hydrolase activity of rat adipose tissue. J. Lipid Res., 15: 291 (1974).

33. Tomarelli, R. M., Meyer, B. J., Weaber, J. R., and Bernhart, F. W.: Effect of positional distribution on the absorption of the fatty acids of human milk and infant formulas. J. Nutr., 95: 583 (1968).

34. Watkins, J. B., Bliss, C. M., Donaldsson, R. M. Jr., and Lester, R.: Characterization of newborn fecal lipid. Pediatrics, 53: 511 (1974).

35. Watkins, J. B., Szczepanik, P., Gould, J. B., Klein, P., and Lester, R.: Bile salt metabolism in the human premature infant. Gastroenterology, 69: 706 (1975).

36. Verger, R., de Haas, G. H., Sarda, L., and Desnuelle, P.: Purification from porcine pancreas of two molecular species with lipase activity. Biochim Biophys. Acta, 188: 272 (1969)

37. Widdowson, E. M.: Absorption and excretion of fat, nitrogen, and minerals from "filled" milks by babies one-week old. Lancet, 2: 1099 (1965).

38. Williamson, S., Finucane, E., Ellis, H., and Gamsu, H. R.: Effect of heat treatment of human milk on absorption of nitrogen, fat, sodium, calcium and phosphorus by preterm infants. Arch. Dis. Child., 53: 555 (1978).

39. Zoppi, G., Andreotti, G., Pajno-Ferrara, F., Njai, D. M., and Gaburro, D. Exocrine pancreas function in premature and fullterm neonates. Pediatr. Res. 6: 880 (1972).

40. Requests for reprints should be addressed to: Dr. Olle Hernell, Department of Pediatrics, University of Umeå, S-901 85 Umeå, Sweden

41. This research was supported by grants from the Swedish Medical Research Council (19X-05708), the Wennergrenska Samfundet, the Swedish Baby Food Fund for Nutritional Research, the Swedish Society of Medical Sciences and the Medical Faculty, University of Umeå.

42. Received for publication August 27, 1981.

43. Accepted for publication March 15, 1982. 